\title{
Systematic model for lean product development implementation in an automotive related com- pany
}

\author{
Daniel Osezua Aikhuele ${ }^{a^{*}}$
}

${ }^{a}$ Faculty of Manufacturing Engineering, Universiti Malaysia Pahang, 26600 Pekan, Malaysia

\begin{tabular}{l}
\hline C H R O N I C L E \\
\hline Article history: \\
Received: February 1, 2017 \\
Received in revised format: \\
March 16, 2017 \\
Accepted: April 24, 2017 \\
Available online: \\
April 25, 2017 \\
\hline Keywords: \\
Lean product development prac- \\
tices \\
Fuzzy Shannon's entropy \\
Modified Technique for Order \\
Preference by Similarity to the \\
Ideal Solution \\
Systematic model \\
Implementation limitations
\end{tabular}
\section{A B S T R A C T}

\begin{abstract}
Lean product development is a major innovative business strategy that employs sets of practices to achieve an efficient, innovative and a sustainable product development. Despite the many benefits and high hopes in the lean strategy, many companies are still struggling, and unable to either achieve or sustain substantial positive results with their lean implementation efforts. However, as the first step towards addressing this issue, this paper seeks to propose a systematic model that considers the administrative and implementation limitations of lean thinking practices in the product development process. The model which is based on the integration of fuzzy Shannon's entropy and Modified Technique for Order Preference by Similarity to the Ideal Solution (M-TOPSIS) model for the lean product development practices implementation with respective to different criteria including management and leadership, financial capabilities, skills and expertise and organization culture, provides a guide or roadmap for product development managers on the lean implementation route.
\end{abstract}

\section{Introduction}

The increasing demands for customized and hybrid products are gradually moving new product development from being a competitive advantage to a necessity in today's fast-growing global market (Carulli et al. 2013). For product development companies to stay competitive in the market they are being pressured to address their product development challenges innovatively, and one way of doing that is through the integration of lean thinking practices in their product development process (Aikhuele \& Turan 2016d). Lean which is an improvement philosophy was first developed by the Toyota Motor Company, primarily to eliminate waste from the production system. However, in recent years, these thinking have been extended to other areas including the product development process. According to John et al. (2014), applying lean thinking practices in new product development can help save the huge resources normally spent fighting sudden quality and reliability issues, and can lead to faster product 
development time, reduction in warranty costs, easier and cheaper manufacturing processes, highquality suppliers products since the supply chain are involved in the development process of the product and finally the creation of an atmosphere and culture of doing things right the first time.

Despite the many benefits and high hopes in the lean strategy, many companies are still struggling, and unable to neither achieve nor sustain substantial positive results with their lean implementation efforts (Stenius 2011; Azizi \& Aikhuele 2015). In the work of León and Farris (2011), they suggested that, one of the major issue affecting the efficient administration and implementation of lean product development practices in companies lies in the absent of a unified and holistic model for assessing the performance of lean product development practices and in tracking their progress as they seek to achieve efficient and effective lean product development process executions. Letens et al. (2011), claim that the poor implementation of lean product development practices is due to the lack of clear understanding of lean thinking and their characteristic practices. While Stenius (2011) suggest that, the lack of lean thinking when implementing lean is the main issue affecting the efficient administration and implementation of lean product development practices, and proposed a framework for the prioritization of lean development actions.

As the first step towards addressing this issue, this paper, however, seeks to propose a systematic model that considers the administrative and implementation limitations of lean thinking practices in the product development process. The model which is based on fuzzy Shannon's entropy and the Modified Technique for Order Preference by Similarity to the Ideal Solution (M-TOPSIS) model originally proposed in (Ren et al. 2007; Aikhuele \& Turan 2016a;b) is applied to the lean product development practices with respective to the criteria; management and leadership, financial capabilities, skills and expertise and organization culture which was initially introduced in (Shah and Ward 2003) for lean manufacturing, which the author believe could provide a guide or roadmap for product development managers on lean implementation route and in the adoption of lean practices in the product development process.

Most of the proposed methods, models and frameworks for implementing lean practices in the lean product development literature have all been conceptual and based on the experience of implementing lean. Extensive literature review shows that there are no systematic methods or model for implementing lean thinking practices in the product development process or models that consider the vulnerabilities, limitations and implementation risk of the practices.

The implementation of the proposed methodology in this study stands as a pioneer multi-criteria approach for assessing lean practices in the product development environment. It is hoped that it will assist product development managers to lead their department as well as the entire organization to leanness. This study technically contributes to process improvement of decision making, modeling, analysis of lean product development practices and the identification and analyzing of administrative and implementation limitations in lean product development process.

The rest of the paper is organized as follows. The following section presents the literature review, preliminaries, research methodology, application of the proposed model and finally discussion, comparison of the result, limitations of the study and conclusion.

\section{Literature Review}

\subsection{Lean product development framework}

Over the last two decades, several papers including the theoretical and practical aspects of the lean product development practices have been published, where some have focused on defining the lean 
product development (Hoppmann et al., 2011), other concentrated on the development of implementation and support models and frameworks which include steps and tools for the implementation of lean product development practices. The focal point of some models and frameworks are reviewed below.

Furuhjelm, et al. (2011), provide input to a generic Lean Product Development framework by defining an explanatory model for effective knowledge enhancement and execution of development projects. The model which consist of a two by two matrix, with value streams, Product Value Stream and the Knowledge Value Stream at one hand, product and the Concept phase and Implementation phase on the other hand serves as a basis for discussing how the Lean principles, Flow, Visualization, Standardization, and Continuous Improvement could be implemented. Wasim et al. (2013) develop a cost modeling system for lean product and process to support a proactive decision-making process as well as in the elimination of mistake in the design stage using lean enablers like the set-based concurrent engineering, mistake proofing (Poka-yoke) and knowledge-based engineering.

Nepal, et al. (2011), through a reflective case study of a lean product development presented a lean transformation framework which was based on 13 lean principles of the Toyota Product Development System and it was implemented in a manufacturing firm in the US, using design structure and cause and effect matrixes for the analysis of the lean transformation and to determine the root causes of wasteful reworks in the company. Hines, et al. (2006) propose a six-step theoretical framework that they hope could serve as a reference point for academic discussion on the development of systemic approaches to the lean product development process, as well as for industry searching for a framework in their new product development process.

Letens, et al. (2011), propose a multilevel framework which captures key lean product development principles at the functional, project, and portfolio levels; tools and practices for implementing the lean product development practices at each level; and also discuss the approaches for managing the interactions between levels. Saad et al. (2013), presents a new approach, A3 thinking approach for solving problems in the product design process. Narayanamurthy (2014), presents the 7A process selection model for guiding the identification and selection of a suitable process for lean implementation. Parry and Turner (2006), develop a lean visual process management tools which serve as communication aids and are used to drive operations and processes in real time. Wang et al. (2012), presents a step-by-step implementation framework for lean product development starting from the marketing research on the product development process, product design through to the launch of the final product, where the framework was aimed at overcoming the weaknesses in the existing framework in terms of reliability and feasibility.

Even with a large number of proposed models and frameworks for implementing lean in the product development process, none of these models and frameworks accounts for the administrative constraint, risk and other limiting factors associated with the lean implementation. The models and frameworks all rely on output from lean assessment to define and design their implementation sequence, route, and startup point regardless of the implementation constraints and limitations. This study intends however, to address this issue by integrating the outcome of the lean assessment with the systematic model that involves all the lean implementation constraints as evaluating criteria for possible implementation strategy (lean practices), thus selecting the optimal lean practice that suits the situation of the organization.

\subsection{Lean product development assessment}

The lean product development assessment which represents the first step of all proposed lean implementation models and frameworks is aimed at defining the current leanness level of the lean practicing organization (Wang et al. 2012). Upon reviewing the lean product development assessment literature and case studies, different assessment models and tools have been found for conducting the lean assessment including (Haque \& Moore, 2004; Al-Ashaab et al., 2015; Mohammadi, 2010; Chase, 2000; 
Sopelana et al., 2012). However, no unique assessment model or tool identified can be said to fit all product development company.

The models and tools which are based on observation, survey and questionnaire, uses sets of typical questions which are arranged in clusters, with each one of them relating to a particular aspect of the assessment. The main different between them however includes; the lean practices assessed, the different metrics and evaluating criteria, the level of details included in them, cost, general implementation approaches and the answering form of the questionnaire questions. For example, some of the models and tools assigned numerical score on a customized scale, between one and five for each of the questions (Al-Ashaab et al., 2015), while other used the value stream mapping approach to determine the current state and then design a future state for series of events (Chase, 2000).

\section{Research methodology}

In this paper, the proposed systematic model which is used to determine the optimal lean practices that suit the organization situation is carried out in two phases that are the lean product development assessment by experts $(E)$ and then the implementation of the M-TOPSIS and fuzzy Shannon entropy model using information obtain from the experts. Each the phase is accomplished following the steps as shown in the flowchart in Fig. 1.

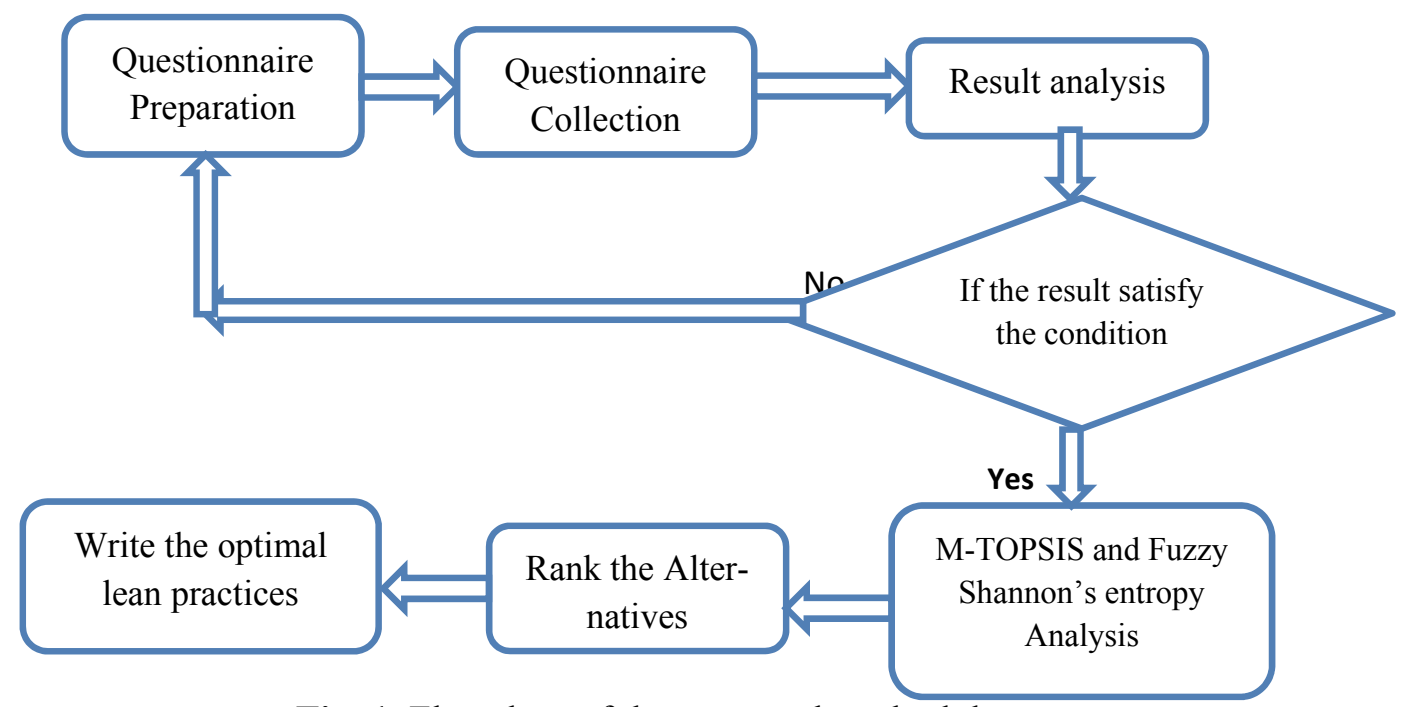

Fig. 1. Flowchart of the proposed methodology

The lean product development assessment by experts is used to determine the current situation of the company, as it relates to the application of lean practices in the product development department, how far it is from full leanness level with special considerations of all the implementation constraints. This phase starts by preparing a questionnaire survey that contains all the implemented lean practices in the company as shown in Table 1, follows the collection and analysis of the questionnaire answers.

The outcome of the analysis is then transferred to the final phase, where the weight of the evaluating criteria are determined by the fuzzy Shannon's entropy method using $\alpha=0.5$ for the sensitivity analysis while the final optimal lean practices that suit the organization situation is determined with the MTOPSIS model with special considerations of the vagueness and uncertainty of the results of the questionnaire. In implementing the M-TOPSIS model, the study will be exploring the application of the Normalized-Hamming distances metric functions for the Fuzzy Positive Ideal Solution (FPIS) and Fuzzy negative Positive Ideal Solution (FNIS). 
Table 1

Extended lean product development framework

\begin{tabular}{lll}
\hline & Lean product development practices & Literature support \\
\hline$\left(\mathrm{A}_{1}\right)$ & Set-based concurrent engineering & (Khan et al. 2011; Aikhuele and Turan 2016c) \\
$\left(\mathrm{A}_{2}\right)$ & Chief Engineer technical leadership & (Aikhuele and Turan 2016d; Al-Ashaab, Shehab, and Alam \\
& & 2010) \\
$\left(\mathrm{A}_{3}\right)$ & Cross-functional teams & (Kim and Kang 2008; Sethi and Al. 2001) \\
$\left(\mathrm{A}_{4}\right)$ & Continuous improvement & (Berger 1997; Yan and Makinde 2011; Kano and Shimizu 2001) \\
$\left(\mathrm{A}_{5}\right)$ & Supplier integration & (Petersen, et al. 2005a; Ragatz, et al. 2002) \\
$\left(\mathrm{A}_{6}\right)$ & Rapid prototyping, simulation, and testing & (Azeem and Gondal 2011; Marvel and Standridge 2013) \\
$\left(\mathrm{A}_{7}\right)$ & A3 Reports Thinking & (Mohd Saad et al. 2013; Lind 2009; Aikhuele and Turan 2016c) \\
$\left(\mathrm{A}_{8}\right)$ & Value stream mapping in product devel- & (Gershenson and Pavnaskar 2003; McManus 2005) \\
& opment (VSM-PD) & (Rodriguez and Ashaab 2007; Maksimovic et al. 2012) \\
$\left(\mathrm{A}_{9}\right)$ & Knowledge-based engineering, & (Krichbaum 2008) (Aikhuele and Turan 2016d) \\
$\left(\mathrm{A}_{10}\right)$ & Standardization & (Pugh 1996; Chen and Tan 1994; Harland and Uddin 2014) \\
$\left(\mathrm{A}_{11}\right)$ & Modularity & (Carulli, Bordegoni, and Cugini 2013; Jurado 2012; Parry and \\
$\left(\mathrm{A}_{12}\right)$ & Visual management & Turner 2006) \\
& &
\end{tabular}

\subsection{Preliminaries}

\section{Fuzzy Set Theory}

Fuzzy set theory was introduced by Zadeh in 1965. Its concept is based on the fact that, the range of truth value of membership function (relations) are the closed interval $[0,1]$ of real numbers (Zadeh 1965). The FST is designed in such a way that it can deal with problems in which source of vagueness and uncertainties are involved. The concept has been successfully utilized in modeling and incorporating imprecise and vague information into decision framework and judgments of decision makers.

Mathematically fuzzy set (e.g. fuzzy set $\tilde{A}$ ) are defined by means of membership function $\mu_{A}(x)$, which associates with each element $x$ in the universe of discourse $X$ a real number in the interval [0,1]. A triangular fuzzy number $\widetilde{A}$ which can be defined by the triplet $\left(l_{1}, m_{1}, u_{1}\right)$, their membership function are express as;

$$
\mu_{A}(x)=\left\{\begin{array}{cc}
\frac{x-1}{m-1} & \text { for } l \leq x \leq m, \\
\frac{u-x}{x-m} & \text { for } m \leq x \leq u, \\
0 & \text { for } x>u,
\end{array}\right.
$$

where $\mathbf{l}, \mathbf{m}$ and $\mathbf{u}$ are real numbers and $\mathbf{l}<\mathbf{m}<\mathbf{u}$. Outside the interval $[\mathbf{l}, \mathbf{u}]$, the pertinence degree is null, and $\mathbf{m}$ represents the point in which the pertinence degree is maximum. Basic arithmetic operations on the triangular fuzzy numbers are shown below;

Definition 1: Given any real number $\mathbf{K}$ and two fuzzy triangular numbers $\tilde{A}=\left(l_{1}, m_{1}, u_{1}\right)$ and $\widetilde{B}=$ $\left(l_{2}, m_{2}, u_{2}\right)$, the main algebraic operations are expressed as follows:

(1) Addition of two triangular fuzzy numbers

$$
\tilde{A}(+) \tilde{B}=\left(l_{1}+l_{2}, m_{1}+m_{2}, u_{1}+u_{2}\right), \quad l_{1} \geq 0, l_{2} \geq 0
$$

(2) Multiplication of two triangular fuzzy numbers

$$
\tilde{A}(\times) \tilde{B}=\left(l_{1} \times l_{2}, m_{1} \times m_{2}, u_{1} \times u_{2}\right), \quad l_{1} \geq 0, l_{2} \geq 0
$$

(3) Subtraction of two triangular fuzzy numbers 


$$
\tilde{A}(-) \tilde{B}=\left(l_{1}-l_{2}, m_{1}-m_{2}, u_{1}-u_{2}\right), \quad l_{1} \geq 0, l_{2} \geq 0
$$

(4) Division of two triangular fuzzy numbers

$$
\tilde{A}(\div) \tilde{B}=\left(l_{1} \div l_{2}, m_{1} \div m_{2}, u_{1} \div u_{2}\right), \quad l_{1} \geq 0, l_{2} \geq 0
$$

(5) Inverse of a triangular fuzzy number

$$
\tilde{A}^{-1}=\left(\frac{1}{u_{1}}, \frac{1}{m_{1}}, \frac{1}{l_{1}}\right) \geq 0
$$

(6) Multiplication of a triangular fuzzy number by a constant

$$
k \times \tilde{A}=\left(k \times l_{1}, k \times m_{1}, k \times u_{1}\right) l_{1} \geq 0, k \geq 0
$$

(7) Division of a triangular fuzzy number by a constant

$$
\frac{\tilde{A}}{k}=\left(\frac{l_{1}}{k}, \frac{m_{1}}{k}, \frac{u_{1}}{k}\right) \quad l_{1} \geq 0, k \geq 0
$$

\subsection{M-TOPSIS and fuzzy Shannon's entropy}

TOPSIS which is an abbreviation of Technique for Order Preference by Similarity to the Ideal Solution was first proposed by Hwang and Yoon. (1981) and ever since it has remained one of the most widely used MCDM method with so many literatures published and in several different field of study including, Chemical science (Soufi et al., 2015), Design (Yang \& Wu, 2008), Engineering (Zhu et al., 2012), Health and medicine (Chou et al., 2012) etc. However, due to some of its limitation, many different improvement and modifications have been proposed, prominently among such improvement is the MTOPSIS model by Ren et al. (2007).

The M-TOPSIS method which was presented to meet the need for a better and simpler method creates an understanding of the inherent relationship between the $\mathrm{R}$ value and alternative evaluation. The $\mathrm{M}-$ TOPSIS method is "described as a process of calculating the distance between the alternatives and the reference points in the $\mathrm{D}+\mathrm{D}$--plane and constructing the $\mathrm{R}$ value to evaluate the quality of alternative" (Ren et al., 2007; Aikhuele \& Turan, 2016a). The M-TOPSIS method is unique for its ability to solve ranking reversals issues in TOPSIS and to evaluate failure when alternatives are symmetrical. This study intends to explore the application of the M-TOPSIS method in a fuzzy environment and to apply the Normalized-Hamming distance method in the analysis, instead of the traditional Euclidean distance method. From the best of our knowledge, this is the first study to apply the M-TOPSIS method and the Normalized-Hamming distance methods for its lean product development analysis.

The M-TOPSIS under a fuzzy environment can be expressed concisely using the following steps:

Step 1. Construct the fuzzy decision matrix $(\widetilde{\mathrm{D}})$ of the alternatives $\left(A_{i}\right)$ with respect to the criteria $\left(C_{i}\right)$ :

$$
\begin{aligned}
& \begin{array}{lllll}
C_{1} & C_{2} & \ldots & C_{m}
\end{array}
\end{aligned}
$$

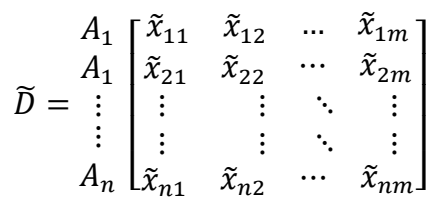


Step 2. Normalize the fuzzy decision matrix of the alternatives ( $\widetilde{D})$ using linear scale transformation. The normalized decision matrix $\widetilde{R}$ is given by:

$$
\tilde{R}=\left[\tilde{r}_{i j}\right]_{m \times n}
$$

where $\tilde{r}_{i j}=\left(\frac{l_{i j}}{u_{j}^{+}}, \frac{m_{i j}}{u_{j}^{+}}, \frac{u_{i j}}{u_{j}^{+}}\right)$and $u_{j}^{+}=\max _{\mathrm{i}} u_{i j}$ (benefit criteria) or, $\tilde{r}_{i j}=\left(\frac{l_{j}^{-}}{u_{i j}}, \frac{l_{j}^{-}}{m_{i j}}, \frac{l_{j}^{-}}{l_{i j}}\right)$ and $l_{j}^{-}=$ $\max _{\mathrm{i}} l_{i j}($ cost criteria)

Step 3. Determine the weight of each of the evaluating criteria. Then compute the weighted normalized decision matrix, $\tilde{V}$, by multiplying the weights of the evaluation criteria, $\widetilde{w}_{j}$, by the elements $\tilde{r}_{i j}$ of the normalized fuzzy decision matrix. The weights of the criteria are determined using the fuzzy Shannon entropy method. But first, data are collected about the alternatives according to the criteria using the linguistic terms as shown in the Table 2 below.

Table 2

Fuzzy numbers for approximating the linguistic variable

\begin{tabular}{cc}
\hline Linguistic terms & Triangular Fuzzy Numbers (TFN) \\
\hline Very low (VL) & $(0.1,0.25,0.3)$ \\
Low (L) & $(0.2,0.3,0.55)$ \\
Good (G) & $(0.3,0.45,0.6)$ \\
High (H) & $(0.5,0.6,0.7)$ \\
Excellent (EX) & $(0.6,0.75,0.9)$ \\
\hline
\end{tabular}

$$
\tilde{V}=\left[\tilde{v}_{i j}\right]_{m \times n}
$$

where $\widetilde{v}_{i j}$ is given by $\tilde{v}_{i j}=\tilde{r}_{i j} \times \widetilde{w}_{j}$ and $\widetilde{w}_{j}$ is the entropy weight.

\section{Fuzzy Shannon's entropy method based on $\propto$-level}

In computing the criteria weight using the $\propto$-cut of TFN, first a decision matrix is formed for the criteria which express the level of importance of each of the criterion using linguistic terms, which are later converted to the TFN $a_{i j}=\left(l_{i j}, m_{i j}, u_{i j}\right)$ and then to crisp value using Eq. (12)

$$
x_{i j}=\frac{\boldsymbol{l}_{\boldsymbol{i j}}+\boldsymbol{m}_{\boldsymbol{i j +}}, \boldsymbol{u}_{\boldsymbol{i j}}}{3}
$$

- Normalized each of the criteria to obtain the projection value $\widetilde{\boldsymbol{P}}_{\boldsymbol{i j}}$;

$\widetilde{\boldsymbol{P}}_{i j}=\frac{x_{i j}}{\sum_{i=0}^{m} x_{i j}}$, where $i=1, \ldots, m, j=1, \ldots, n$.

Thus, the projective matrix which represents the relative weight of each of criterion from the expert's assessment is expressed as;

- Compute the entropy values $\boldsymbol{E} \boldsymbol{p}_{\boldsymbol{j}}$;

$$
\boldsymbol{E} \boldsymbol{p}_{j}=-\boldsymbol{k} \sum_{i=\mathbf{0}}^{m} \widetilde{\boldsymbol{P}}_{i j} \mathbf{I n} \widetilde{\boldsymbol{P}}_{i j}, j=\mathbf{1}, \ldots, \boldsymbol{n}
$$

where $k$ is constant and is defined as $\boldsymbol{k}=(\operatorname{In} \boldsymbol{m})^{-\mathbf{1}}$, if $\widetilde{\boldsymbol{P}}_{\boldsymbol{i j}}=\mathbf{0}$, then $\widetilde{\boldsymbol{P}}_{\boldsymbol{i j}} \mathbf{I n} \widetilde{\boldsymbol{P}}_{\boldsymbol{i j}}=\mathbf{0}$

- Compute the degree of diversification, $\boldsymbol{d}_{\boldsymbol{j}}$ and finally the criteria weight $\boldsymbol{w}_{\boldsymbol{j}}$;

$$
d_{j}=1-E p_{j}, \quad w_{j}=\frac{d_{j}}{\sum_{k=1}^{n} d_{k}}, \quad(j=1, \ldots, n)
$$

Step 4. Define the fuzzy positive ideal solution (FPIS, $\mathbf{A}^{+}$) and the fuzzy negative ideal solution (FNIS, $\mathbf{A}^{-}$) 


$$
\begin{aligned}
& 344 \\
A^{+} & =\left\{\tilde{v}_{l}^{+}, \tilde{v}_{j}^{+}, \cdots, \tilde{v}_{m}^{+}\right\} \\
A^{-} & =\left\{\tilde{v}_{l}^{-}, \tilde{v}_{j}^{-}, \cdots, \tilde{v}_{m}^{-}\right\}
\end{aligned}
$$

Step 5. Compute the distances $d_{j}^{+}$and $d_{j}^{-}$of each alternative from FPIS, $\mathbf{A}^{+}$and from FNIS, A'using $\tilde{\mathrm{v}}_{\mathrm{j}}^{+}$and $\tilde{\mathrm{v}}_{\mathrm{j}}^{-}$respectively

Let $d(\tilde{\tilde{A}}, \widetilde{B})_{L 2_{i}}$ represents the distance point between two fuzzy numbers $(\tilde{\tilde{A}}, \widetilde{B})$. According to the Normalized-Hamming distance method, the distance for the two fuzzy numbers in a fuzzy environment is shown respectively in the equations below $(\mathrm{Li}, 2013)$.

- Normalized-Hamming distance method $\left(\mathrm{L}_{2}\right)$

$$
d(\tilde{\tilde{A}}, \widetilde{B})_{\mathrm{L} 2_{i+}}=\sqrt{\sum_{i=1}^{n} \frac{1}{6}\left[\left(l_{i j}-\tilde{v}_{j}^{+}\right)^{2}+4\left(m_{i j}-\tilde{v}_{j}^{+}\right)^{2}+\left(u_{i j}-\tilde{v}_{j}^{+}\right)^{2}\right]}
$$

Similarly,

$$
d(\tilde{\tilde{A}}, \widetilde{B})_{\mathrm{L} 2_{i_{-}}}=\sqrt{\sum_{i=1}^{n} \frac{1}{6}\left[\left(l_{i j}-\tilde{v}_{j}^{-}\right)^{2}+4\left(m_{i j}-\tilde{v}_{j}^{-}\right)^{2}+\left(u_{i j}-\tilde{v}_{j}^{-}\right)^{2}\right]}
$$

Step 6. Set a point to say $A$ as the optimized ideal references point for $(A, B)$, for each of the distance method such that;

$\mathrm{A}\left(\min d(\tilde{\tilde{A}}, \widetilde{B})_{\mathrm{L} 2 i}^{+}, \max d(\tilde{\tilde{A}}, \widetilde{B})^{-}{ }_{\mathrm{L} 2 i}\right)$

Then calculate the distances from each alternative. The relative closeness $R_{i}$ to the ideal solution is calculated for the distances method as shown below;

$$
R_{i}=\sqrt{\left[\left(d(\tilde{\tilde{A}}, \widetilde{B})_{L 2_{i}}^{+}-\min d(\tilde{\tilde{A}}, \widetilde{B})_{L 2_{i}}^{+}\right)^{2}+\left(d(\tilde{\tilde{A}}, \widetilde{B})_{L 2_{i}}^{-}-\max d(\tilde{\tilde{A}}, \widetilde{B})_{L 2_{i}}^{-}\right)^{2}\right]}
$$

Step 7. Rank the preference order. For ranking of alternative, $R_{i}$ should be ranked in increasing order. However if there are two alternatives $\mathrm{A}_{1}$ and $\mathrm{A}_{2}, R_{1}=R_{2}$ where $1 \neq 2$, then $R_{i}$ is calculated using equation (20) then choose the better one with the smaller $R_{i}$ value for all three method.

$$
R_{i}=d(\tilde{\tilde{A}}, \widetilde{B})_{l 2_{i}}^{+}-\min d(\tilde{\tilde{A}}, \widetilde{B})^{+}
$$

Step 8. Rank the preference order of the alternatives according to their relative closeness to the ideal solution. The greater value of relative closeness represents a higher-ranking order among alternatives and will be chosen as a recommended alternative.

\section{Numerical Case study of an automotive related company}

In this section, we put the proposed systematic model into practice at a dedicated company that specialized in designing, developing and manufacturing automotive related parts in Pekan Malaysia. We intend to demonstrate how the model can be used in selecting optimal or the most appropriate lean practices for the company while considering their lean implementation challenges. The authors believe 
the starting point of achieving leanness in the company should be through the adoption of a systematic approach, thinking lean while implementing lean (Stenius, 2011), that is prioritizing the lean product development practices while considering the identified lean challenges and limitations in the past. As stated above the administrative and lean implementation limitations which serve as the criteria are described below.

- Management and leadership $\left(\mathrm{C}_{1}\right)$ : According to Karlsson and Ahlström (Karlsson \& Ahlström, 2013) the managerial overemphasis on R\&D in development projects hampers efforts to achieve cross-functional integration, which is at the center of the lean product development initiative. A Cross-functional team cannot perform effectively in the present of sequential view on the development process rather on iterative view.

- Financial capabilities $\left(\mathrm{C}_{2}\right)$ : The initial resources for introducing and implementing the different lean practices can hamper its implementation as most companies are faced with restricted resources in terms of finance and manpower. Most especially small and medium enterprise (SME) like our case company.

- Skills and expertise $\left(\mathrm{C}_{3}\right)$ : Product development teams often develop specialized knowledge and skills, which often make them wanting to resist any changes away from existing specialized knowledge since they've invested so much in such knowledge.

- Organization culture $\left(\mathrm{C}_{4}\right)$ : According to Liker (Liker, 2004) one of the biggest challenge when becoming Lean is "how to create an aligned organization of individuals who each have the DNA of the organization and are continually learning together to add value to the customer"

The implementation of the proposed systematic model is summarized as follows;

Step 1: The research uses the linguistic variables and then TFN to express the ratings of the lean practices $A_{i}$ with respect to each of the criterion $C_{j}$ to form the decision matrix $(\widetilde{D})$ as shown in Tables (34).

Table 3

Experts ratings with Linguistic terms

\begin{tabular}{|c|c|c|c|c|c|c|c|c|c|c|c|c|}
\hline $\mathbf{C}_{\mathbf{i}}$ & $\mathbf{E}_{1}$ & $\mathbf{E}_{2}$ & $\mathbf{E}_{3}$ & $\mathbf{E}_{1}$ & $\mathbf{E}_{2}$ & $\mathbf{E}_{3}$ & $\mathbf{E}_{1}$ & $\mathbf{E}_{2}$ & $\mathbf{E}_{3}$ & $\mathbf{E}_{1}$ & $\mathbf{E}_{2}$ & $\mathbf{E}_{3}$ \\
\hline & & $\mathrm{C} 1$ & & & $\mathrm{C} 2$ & & & $\mathrm{C} 3$ & & & $\mathrm{C} 4$ & \\
\hline $\mathbf{A}_{1}$ & $\bar{L}$ & $\mathrm{G}$ & VL & $\mathrm{H}$ & $\mathrm{L}$ & $\mathrm{H}$ & VL & $\mathrm{H}$ & $\mathrm{G}$ & $\mathrm{G}$ & $\mathrm{L}$ & $\mathrm{VL}$ \\
\hline $\mathbf{A}_{2}$ & $\mathrm{H}$ & $\mathrm{H}$ & VL & EX & $\mathrm{G}$ & EX & L & EX & $\mathrm{H}$ & VL & $\mathrm{G}$ & $\mathrm{L}$ \\
\hline $\mathbf{A}_{3}$ & $\mathrm{EX}$ & EX & $\mathrm{L}$ & VL & $\mathrm{H}$ & $\mathrm{H}$ & $\mathrm{G}$ & $\mathrm{H}$ & $\mathrm{EX}$ & $\mathrm{L}$ & $\mathrm{H}$ & $\mathrm{G}$ \\
\hline $\mathbf{A}_{4}$ & $\mathrm{H}$ & $\mathrm{H}$ & $\mathrm{G}$ & L & G & $\mathrm{G}$ & L & L & VL & $\mathrm{G}$ & $\mathrm{L}$ & VL \\
\hline A5 & $\mathrm{H}$ & G & $\mathrm{L}$ & $\mathrm{G}$ & $\mathrm{H}$ & G & $\mathrm{H}$ & G & $\mathrm{L}$ & $\mathrm{L}$ & G & $\mathrm{L}$ \\
\hline $\mathbf{A}_{6}$ & VL & G & $\mathrm{H}$ & $\mathrm{H}$ & EX & $\mathrm{H}$ & EX & L & VL & $\mathrm{G}$ & $\mathrm{H}$ & $\mathrm{G}$ \\
\hline $\mathbf{A}_{7}$ & $\mathrm{~L}$ & $\mathrm{H}$ & VL & EX & $\mathrm{H}$ & $\mathrm{H}$ & $\mathrm{L}$ & $\mathrm{G}$ & $\mathrm{L}$ & $\mathrm{H}$ & $\mathrm{G}$ & $\mathrm{H}$ \\
\hline A8 & $\mathrm{H}$ & EX & L & VL & EX & EX & $\mathrm{G}$ & $\mathrm{H}$ & $\mathrm{G}$ & $\mathrm{G}$ & $\mathrm{H}$ & L \\
\hline $\mathbf{A}_{9}$ & VL & $\mathrm{H}$ & $\mathrm{H}$ & VL & $\mathrm{H}$ & $\mathrm{H}$ & VL & G & VL & $\mathrm{G}$ & VL & $\mathrm{G}$ \\
\hline $\mathbf{A}_{10}$ & $\mathrm{~L}$ & VL & EX & $\mathrm{L}$ & EX & EX & $\mathrm{L}$ & L & $\mathrm{L}$ & $\mathrm{H}$ & $\mathrm{L}$ & $\mathrm{H}$ \\
\hline $\mathbf{A}_{11}$ & $\mathrm{G}$ & $\mathrm{L}$ & $\mathrm{H}$ & VL & $\mathrm{H}$ & $\mathrm{H}$ & $\mathrm{G}$ & $\mathrm{G}$ & $\mathrm{G}$ & $\mathrm{EX}$ & $\mathrm{G}$ & $\mathrm{H}$ \\
\hline$A_{12}$ & VL & $\mathrm{H}$ & $\mathrm{G}$ & $\mathrm{H}$ & $\mathrm{H}$ & $\mathrm{G}$ & VL & $\mathrm{H}$ & $\mathrm{H}$ & $\mathrm{L}$ & EX & $\mathrm{G}$ \\
\hline
\end{tabular}

Table 4

Decision matrix for the proposed fuzzy model

\begin{tabular}{lcccc}
\hline & C1 & C2 & C3 & C4 \\
\hline $\mathbf{A}_{1}$ & $(0.20,0.33,0.48)$ & $(0.40,0.50,0.65)$ & $(0.30,0.43,0.53)$ & $(0.20,0.33,0.48)$ \\
$\mathbf{A}_{\mathbf{2}}$ & $(0.37,0.48,0.57)$ & $(0.47,0.65,0.80)$ & $(0.43,0.55,0.72)$ & $(0.20,0.33,0.48)$ \\
$\mathbf{A}_{\mathbf{3}}$ & $(0.43,0.55,0.67)$ & $(0.27,0.40,0.58)$ & $(0.17,0.28,0.47)$ & $(0.20,0.33,0.48)$ \\
$\mathbf{A}_{\mathbf{4}}$ & $(0.33,0.45,0.62)$ & $(0.37,0.50,0.63)$ & $(0.33,0.45,0.62)$ & $(0.23,0.35,0.57)$ \\
$\mathbf{A}_{\mathbf{5}}$ & $(0.30,0.43,0.53)$ & $(0.53,0.65,0.77)$ & $(0.30,0.43,0.58)$ & $(0.37,0.50,0.63)$ \\
$\mathbf{A}_{6}$ & $(0.27,0.38,0.52)$ & $(0.53,0.65,0.77)$ & $(0.23,0.35,0.57)$ & $(0.43,0.55,0.67)$ \\
$\mathbf{A}_{7}$ & $(0.43,0.55,0.72)$ & $(0.43,0.58,0.70)$ & $(0.37,0.50,0.63)$ & $(0.33,0.45,0.62)$ \\
$\mathbf{A}_{\mathbf{8}}$ & $(0.37,0.48,0.57)$ & $(0.37,0.48,0.57)$ & $(0.17,0.32,0.40)$ & $(0.23,0.38,0.50)$ \\
$\mathbf{A}_{9}$ & $(0.30,0.43,0.58)$ & $(0.47,0.60,0.78)$ & $(0.20,0.30,0.55)$ & $(0.40,0.50,0.65)$ \\
$\mathbf{A}_{10}$ & $(0.33,0.45,0.62)$ & $(0.37,0.48,0.57)$ & $(0.30,0.45,0.60)$ & $(0.47,0.60,0.73)$ \\
$\mathbf{A}_{11}$ & $(0.30,0.43,0.58)$ & $(0.10,0.25,0.30)$ & $(0.23,0.37,0.43)$ & $(0.43,0.55,0.67)$ \\
$\mathbf{A}_{\mathbf{1 2}}$ & $(0.40,0.50,0.65)$ & $(0.27,0.40,0.58)$ & $(0.33,0.45,0.62)$ & $(0.37,0.50,0.68)$ \\
\hline
\end{tabular}


Step 2: Same as Step 1, decision matrix for the criteria are constructed, using linguistic variables, TFN, and then crisp values to express the level of importance of each of the criterion. Thereafter the criteria weight is calculated using Eqs. (12-15), the result of the evaluations are shown in Tables (5-7).

Table 5

Aggregated decision matrix for fuzzy Shannon's Entropy

\begin{tabular}{ccccccccc}
\hline & $\mathbf{C}_{\mathbf{1}}$ & $\mathbf{C}_{\mathbf{2}}$ & $\mathbf{C}_{\mathbf{3}}$ & $\mathbf{C}_{\mathbf{4}}$ & $\mathbf{C}_{\mathbf{1}}$ & $\mathbf{C}_{\mathbf{2}}$ & $\mathbf{C}_{\mathbf{3}}$ & $\mathbf{C}_{\mathbf{4}}$ \\
\hline $\mathbf{E}_{\mathbf{1}}$ & VL & H & EX & H & $(0.1,0.25,0.3)$ & $(0.5,0.6,0.7)$ & $(0.6,0.75,0.9)$ & $(0.5,0.6,0.7)$ \\
$\mathbf{E}_{\mathbf{2}}$ & L & EX & H & H & $(0.2,0.3,0.55)$ & $(0.6,0.75,0.9)$ & $(0.5,0.6,0.7)$ & $(0.5,0.6,0.7)$ \\
$\mathbf{E}_{3}$ & G & VL & EX & L & $(0.3,0.45,0.6)$ & $(0.1,0.25,0.3)$ & $(0.6,0.75,0.9)$ & $(0.2,0.3,0.55)$ \\
$\mathbf{E}_{4}$ & L & G & EX & G & $(0.2,0.3,0.55)$ & $(0.3,0.45,0.6)$ & $(0.1,0.25,0.3)$ & $(0.2,0.3,0.55)$ \\
\hline
\end{tabular}

Table 6

Crisp values and criterion projection value

\begin{tabular}{lcccccccc}
\hline & $\mathbf{C}_{\mathbf{1}}$ & $\mathbf{C}_{\mathbf{2}}$ & $\mathbf{C}_{\mathbf{3}}$ & $\mathbf{C}_{\boldsymbol{4}}$ & $\widetilde{\boldsymbol{P}}_{\boldsymbol{C}_{\boldsymbol{1}}}$ & $\widetilde{\boldsymbol{P}}_{\boldsymbol{C}_{\mathbf{2}}}$ & $\widetilde{\boldsymbol{P}}_{\boldsymbol{C}_{\mathbf{3}}}$ & $\widetilde{\boldsymbol{P}}_{\boldsymbol{C}_{\mathbf{4}}}$ \\
\hline $\mathbf{E}_{\mathbf{1}}$ & $(0.217)$ & $(0.600)$ & $(0.750)$ & $(0.600)$ & 0.100 & 0.277 & 0.346 & 0.277 \\
$\mathbf{E}_{\mathbf{2}}$ & $(0.350)$ & $(0.750)$ & $(0.600)$ & $(0.600)$ & 0.152 & 0.326 & 0.261 & 0.261 \\
$\mathbf{E}_{\mathbf{3}}$ & $(0.450)$ & $(0.217)$ & $(0.750)$ & $(0.350)$ & 0.255 & 0.123 & 0.424 & 0.198 \\
$\mathbf{E}_{\mathbf{4}}$ & $(0.350)$ & $(0.450)$ & $(0.217)$ & $(0.350)$ & 0.256 & 0.329 & 0.159 & 0.256 \\
\hline
\end{tabular}

Table 7

Shannon's Entropy weight

\begin{tabular}{lccc}
\hline & $\boldsymbol{E p}_{\boldsymbol{j}}$ & $\boldsymbol{d}_{\boldsymbol{j}}$ & $\boldsymbol{w}_{\boldsymbol{j}}$ \\
\hline $\mathbf{C}_{\mathbf{1}}$ & 0.876 & 0.124 & 0.725 \\
$\mathbf{C}_{2}$ & 0.970 & 0.030 & 0.175 \\
$\mathbf{C}_{3}$ & 0.991 & 0.009 & 0.053 \\
$\mathbf{C}_{4}$ & 0.992 & 0.008 & 0.047 \\
\hline
\end{tabular}

In following the other implementation steps as stated above (i.e. Steps 4-8), the optimal lean practices with respects to the evaluating criteria are calculated. The results for M-TOPSIS model for the alternatives and the rankings are shown in Table 8.

Table 8

The M-TOPSIS result

\begin{tabular}{|c|c|c|c|c|c|c|}
\hline & $(\widetilde{\widetilde{A}}, \widetilde{B})_{\mathrm{L}}$ & $d(\widetilde{\widetilde{A}}, \widetilde{B})_{\mathrm{L} 2_{i}}$ & $\overline{R_{i}}$ & Ranking & Fuzzy TOPSIS & Ranking \\
\hline $\mathbf{A}_{1}$ & 1.826 & 0.266 & 0.205 & 11 & 0.127 & 11 \\
\hline $\mathbf{A}_{2}$ & 1.769 & 0.368 & 0.090 & 4 & 0.172 & 4 \\
\hline $\mathbf{A}_{3}$ & 1.779 & 0.409 & 0.056 & 2 & 0.187 & 2 \\
\hline $\mathbf{A}_{4}$ & 1.789 & 0.351 & 0.113 & 6 & 0.164 & 6 \\
\hline A5 & 1.782 & 0.334 & 0.126 & 8 & 0.158 & 8 \\
\hline $\mathbf{A}_{6}$ & 1.794 & 0.308 & 0.155 & 10 & 0.147 & 10 \\
\hline $\mathbf{A}_{7}$ & 1.753 & 0.423 & 0.033 & 1 & 0.194 & 1 \\
\hline A8 & 1.790 & 0.359 & 0.105 & 5 & 0.167 & 5 \\
\hline A9 & 1.786 & 0.339 & 0.123 & 7 & 0.159 & 7 \\
\hline $\mathbf{A}_{10}$ & 1.785 & 0.350 & 0.112 & 6 & 0.164 & 6 \\
\hline $\mathbf{A}_{11}$ & 1.818 & 0.324 & 0.149 & 9 & 0.151 & 9 \\
\hline $\mathbf{A}_{12}$ & 1.780 & 0.381 & 0.081 & 3 & 0.176 & 3 \\
\hline
\end{tabular}

\subsection{Discussion}

The determination of the optimal lean practices with respect to administrative and lean implementation limitations; management and leadership, financial capabilities, skills and expertise and organization culture, has been realized. According to the relative closeness $R_{i}$ to the ideal solution calculated, the 
ranking of the lean practice are in the $\operatorname{order} A_{1}>A_{7}>A_{13}>A_{12}>A_{6}>A_{10}>A_{5}>A_{11}>$ $A_{9}>A_{2}>A_{14}>A_{4}>A_{8}>A_{3}$.

The main advantage of the proposed systematic model is that it makes the decision to implement a particular lean practice over another within the product development environment with respect to the identified administrative and lean implementation limitations more reliable and more objective.

The results from the systematic model are compared with that of fuzzy TOPSIS under the same condition with the same weight values, the comparison which is based on the ranking of the methods found that the ranking for the fuzzy TOPSIS method shows that the M-TOPSIS method is quite better intense of ranking of the lean practices. The results are shown in Table 8 above. According to the fuzzy TOPSIS method, A 7 outperformed other lean practices with $A_{4}$ and $A_{10}$ having the same rank, unlike the MTOPSIS where the ranks for are the alternatives are quite clear.

\subsection{Limitations and future scope of the research work}

The results from the proposed systematic model are limited to the experiences and assessment from the case company. The values used for the evaluation in the analysis are based on the knowledge and assessment from the engaged experts and company. The scores for the relationship among the alternatives were all obtained from the experts. Hence, the accuracy of the result depends on the expert's opinion. To further improve the result, more research is certainly called for within the context of the study with more companies involved and more experts interviewed and the method can be applied in other industries.

\section{Conclusion}

In this paper, we proposed a systematic model based on the integration of fuzzy Shannon's Entropy method and M-TOPSIS model under a fuzzy environment, using Normalized-Hamming distance method for the lean product development practice.

The study contributes to the lean product development literature by identifying some core lean practices that have found applications in the lean product development process in companies which hitherto have not been reported in the lean product development literature. Also, it provides a guide or roadmap for product development managers on the lean implementation route, intense of, the adoption of lean practices in the product development process with respect to the identified administrative and lean implementation limitations.

In handling the subjectivity and vagueness in the data provided by the experts and the case company, a set of fuzzy numbers for approximating linguistic variable values was developed and was used in collecting the evaluation data. The importance of the Fuzzy number concept in this work lies in the fact that it helps in accounting for the degree of inherent uncertainty in the evaluation which was never considered in the previous assessment in the literature. Also, it serves as a means of incorporating uncertainty into parameters, properties, geometry or initial conditions of the evaluating method.

The result from the analysis shows that set-based concurrent engineering is ranked as the most effective lean practice, follow by rapid prototyping, simulation and testing and Modularity etc. The result from this study will serve as an advisory system and a guide for product development managers planning to evaluate their current practices, in the allocation of reasonable resources and in the implementation of lean practices in the product development with special consideration of uncertainties, administrative and lean implementations limitations. 


\section{Reference}

Aikhuele, D. O., \& Turan, F. B. M. (2016a). An improved methodology for multi-criteria evaluations in the shipping industry. Brodogradnja, 67(3), 59-72.

Aikhuele, D. O., \& Faiz, M. T. (2016b). An interval fuzzy-valued M-TOPSIS model for design concept selection. The National Conference for Postgraduate Research 2016, Universiti Malaysia Pahang, 374-84.

Aikhuele, D. O., \& Turan, F. M. (2016c). A Hybrid Fuzzy Model for Lean Product Development Performance Measurement. In IOP Conference Series: Materials Science and Engineering (Vol. 114, No. 1, p. 012048). IOP Publishing.

Aikhuele, D. O., \& Turan, F. M. (2016d). Proposal for a Conceptual Model for Evaluating Lean Product Development Performance: A Study of LPD Enablers in Manufacturing Companies. In IOP Conference Series: Materials Science and Engineering (Vol. 114, No. 1, p. 012047). IOP Publishing.

Al-Ashaab, A., Golob, M., Urrutia, U. A., Gourdin, M., Petritsch, C., Summers, M., \& El-Nounu, A. (2016). Development and application of lean product development performance measurement tool. International Journal of Computer Integrated Manufacturing, 29(3), 342-354.

Al-Ashaab, A., Shehab, E., Alam, R., Sopelana, A., Sorli, M., Flores, M., ... \& James-Moore, M. (2010). The conceptual leanPPD model. In New World Situation: New Directions in Concurrent Engineering (pp. 339-346). Springer London.

Azeem, M., \& Gondal, M. B. (2011). Prototype framework: prototypes, prototyping and piloting in terms of quality insurance. Academic Research International 1(2), 301-307.

Azizi, A., \& Aikhuele, D. O. (2015, March). An integrated model of Kano and quality function deployment for evaluation of lean production tools in assembly environment. In Industrial Engineering and Operations Management (IEOM), 2015 International Conference on (pp. 1-6). IEEE.

Berger, A. (1997). Continuous improvement and kaizen: standardization and organizational designs. Integrated manufacturing systems, 8(2), 110-117.

Carulli, M., Bordegoni, M., \& Cugini, U. (2013). An approach for capturing the voice of the customer based on virtual prototyping. Journal of Intelligent Manufacturing, 24(5), 887-903.

Chase, J. P. (2000). Measuring value in product development. Massachusetts Institute of Technology.

Chen, S. M., \& Tan, J. M. (1994). Handling multicriteria fuzzy decision-making problems based on vague set theory. Fuzzy sets and systems, 67(2), 163-172.

Chou, S. Y., Vincent, F. Y., Dewabharata, A., \& Dat, L. Q. (2012, November). A fuzzy TOPSIS approach for medical provider selection and evaluation. In Fuzzy Theory and it's Applications (iFUZZY), 2012 International Conference on (pp. 322-326). IEEE.

Furuhjelm, J., Swan, H., \& Tingström, J. (2011, August). Creating value through lean product development: applying lean principles. In Proceedings of the 18th International Conference on Engineering Design (ICED 11)(8 pp.) Copenhagen: The Design Society.

Gershenson, J. K., \& Pavnaskar, S. J. (2003). Eight Basic Lean Product Development Tools. In DS 31 : Proceedings of ICED 03, the 14th International Conference on Engineering Design, Stockholm.

Haque, B., \& Moore, M. J. (2004). Measures of performance for lean product introduction in the aerospace industry. Proceedings of the Institution of Mechanical Engineers, Part B: Journal of Engineering Manufacture, 218(10), 1387-1398.

Harland, P. E., \& Uddin, Z. (2014). Effects of product platform development: fostering lean product development and production. International Journal of Product Development 18, 19(5-6), 259-285.

Hines, P., Francis, M., \& Found, P. (2006). Towards lean product lifecycle management: a framework for new product development. Journal of Manufacturing Technology Management, 17(7), 866-887.

Hoppmann, J., Rebentisch, E., Dombrowski, U., \& Zahn, T. (2011). A framework for organizing lean product development. Engineering Management Journal, 23(1), 3-15.

Hwang, C. L., \& Yoon, K. (1981). Multiple Attribute Decision Making Methods and Applications. Berlin: Springer.

Paschkewitz, J. J. (2014, January). Risk management in Lean Product Development. In Reliability and Maintainability Symposium (RAMS), 2014 Annual (pp. 1-6). IEEE. 
Jurado, M. C. (2012). Visual Planning in Lean Product Development. KTH Royal Institute of Technology.

Kano, Shigeto, and Hirokazu Shimizu. 2001. "A Guide to GD3 Activities and DRBFM Technique to Prevent Trouble." Vehicle Technology Dept No. 1, Toyota Motor Corporation. Vol. Version 5.

Karlsson, C., \& Ahlström, P. (1996). The difficult path to lean product development. Journal of product innovation management, 13(4), 283-295.

Khan, M., Al-Ashaab, A., Doultsinou, A., Shehab, E., Ewers, P., \& Sulowski, R. (2011). Set-based concurrent engineering process within the LeanPPD environment. In Improving Complex Systems Today (pp. 433-440). Springer London.

Bo-Young, K. (2008). Cross-functional cooperation with design teams in new product development. International Journal of Design, 2(3), 43-54.

Krichbaum, B. D. (2008). Standardized work: The power of consistency standardized work: The power of consistency standardized work : The Principles.

Li, L., \& Fan, G. (2014). Fuzzy MADM with triangular numbers for project investment model based on left and right scores. Research Journal of Applied Sciences, Engineering, and Technology, 7(13), 2793-97.

León, H. C. M., \& Farris, J. A. (2011). Lean product development research: Current state and future directions. Engineering Management Journal, 23(1), 29-51.

Letens, G., Farris, J. A., \& Van Aken, E. M. (2011). A multilevel framework for lean product development system design. Engineering Management Journal, 23(1), 69-85.

Li, M. (2013). A multi-criteria group decision making model for knowledge management system selection based on TOPSIS with multiple distances in fuzzy environment. Kybernetes, 42(8), 12181234.

Liker, J.K. (2004). The Toyota Way, 14 Management Principles from the World's Greatest Manufacturer. New York: McGraw-Hill.

Lind, M. (2009). Lean Product Development and PLM's Supporting Role. Aras Corporate.

Maksimovic, M., Al-Ashaab, A., Sulowski, R., \& Shehab, E. (2012, December). Knowledge visualization in product development using trade-off curves. In Industrial Engineering and Engineering Management (IEEM), 2012 IEEE International Conference on (pp. 708-711). IEEE.

Marvel, J. H., \& Standridge, C. R. (2009). Simulation-enhanced lean design process. Journal of Industrial Engineering and Management, 2(1), 90-113.

McManus, H. L. (2005). Product Development Value Stream Mapping (PDVSM) Manual Release 1.0. Massachusetts Institute of Technology, no. September.

Mohammadi, A. (2010). Lean Product Development -Performance Measurement System. Gothenburg: Gothenburg University, 1-64.

Saad, N. M., Al-Ashaab, A., Maksimovic, M., Zhu, L., Shehab, E., Ewers, P., \& Kassam, A. (2013). A3 thinking approach to support knowledge-driven design. The International Journal of Advanced Manufacturing Technology, 68(5-8), 1371-1386.

Narayanamurthy, G. (2014). 7A model - A process selection guide for lean implementation. In Proceedings of the Twenty-Fifth Annual Conference Production and Operations Management Society (POM 2014), 9-12 May 2014, Atlanta, USA., 1-13.

Nepal, B. P., Yadav, O. P., \& Solanki, R. (2011). Improving the NPD process by applying lean principles: A case study. Engineering Management Journal, 23(1), 52-68.

Parry, G. C., \& Turner, C. E. (2006). Application of lean visual process management tools. Production Planning \& Control, 17(1), 77-86.

Petersen, K. J., Handfield, R. B., \& Ragatz, G. L. (2005). Supplier integration into new product development: coordinating product, process and supply chain design. Journal of operations management, 23(3), 371-388.

Pugh, S. (1996). Creating Innovative Products Using Total Design: The Living Legacy of Stuart Pugh. Reading, MA: Addison-Wesley.

Ragatz, G. L., Handfield, R. B., \& Petersen, K. J. (2002). Benefits associated with supplier integration 
into new product development under conditions of technology uncertainty. Journal of business research, 55(5), 389-400.

Ren, L., Zhang, Y., Wang, Y., \& Sun, Z. (2007). Comparative analysis of a novel M-TOPSIS method and TOPSIS. Applied Mathematics Research eXpress, 2007, abm005.

Rodriguez, K., \& Al-Ashaab, A. (2007). Knowledge web-based system to support e-manufacturing of injection moulded products. International journal of manufacturing technology and management, 10(4), 400-418.

Sethi, R., Smith, D. C., \& Park, C. W. (2001). Cross-functional product development teams, creativity, and the innovativeness of new consumer products. Journal of marketing research, 38(1), 73-85.

Shah, R., \& Ward, P. T. (2003). Lean manufacturing: context, practice bundles, and performance. Journal of operations management, 21(2), 129-149.

Sopelana, A., Flores, M., Martinez, L., Flores, K., \& Sorli, M. (2012, June). The application of an assessment tool for lean product development: an exploratory study in Spanish Companies. In Engineering, Technology and Innovation (ICE), 2012 18th International ICE Conference on (pp. 110). IEEE.

Dehghani Soufi, M., Ghobadian, B., Najafi, G., Sabzimaleki, M. R., \& Yusaf, T. (2015). TOPSIS multicriteria decision modeling approach for biolubricant selection for two-stroke petrol engines. Energies, 8(12), 13960-13970.

Stenius, P. (2011). Making Lean Work Leaner by Prioritizing Actions and Moving Promptly into Implementation. Reddal-BusinessDeveloperNewsletter.

Wang, L., Ming, X. G., Kong, F. B., Li, D., \& Wang, P. P. (2011). Focus on implementation: a framework for lean product development. Journal of Manufacturing Technology Management, 23(1), 424.

Wasim, A., Shehab, E., Abdalla, H., Al-Ashaab, A., Sulowski, R., \& Alam, R. (2013). An innovative cost modelling system to support lean product and process development. The International Journal of Advanced Manufacturing Technology, 65(1-4), 165-181.

Yan, B., \& Makinde, O. D. (2011). Impact of continuous improvement on new product development within SMEs in the Western Cape, South Africa. African Journal of Business Management, 5(6), 2220 .

Yang, C., \& Wu, Q. (2008, October). Decision model for product design based on fuzzy TOPSIS method. In Computational Intelligence and Design, 2008. ISCID'08. International Symposium on (Vol. 2, pp. 342-345). IEEE.

Zadeh, L.A. (1965). Fuzzy sets. Information and Control, 8, 338-53.

Zhu, X., Wang, F., Liang, C., Li, J., \& Sun, X. (2012). Quality credit evaluation based on TOPSIS: Evidence from air-conditioning market in China. Procedia Computer Science, 9, 1256-1262.

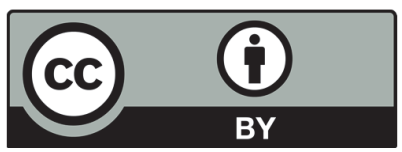

(C) 2017 by the authors; licensee Growing Science, Canada. This is an open access article distributed under the terms and conditions of the Creative Commons Attribution (CC-BY) license (http://creativecommons.org/licenses/by/4.0/). 